Original article

\title{
Smoking and FGFR2 rs2981582 variant independently modulate male breast cancer survival: A population-based study in Tuscany, Italy
}

\author{
Ines Zanna a, Valentina Silvestri ${ }^{\mathrm{b}}$, Domenico Palli ${ }^{\mathrm{a},{ }^{*}}$, Alessandro Magrini ${ }^{\mathrm{a}}$, \\ Piera Rizzolo ${ }^{\mathrm{b}}$, Calogero Saieva ${ }^{\mathrm{a}}$, Veronica Zelli ${ }^{\mathrm{b}}$, Benedetta Bendinelli ${ }^{\mathrm{a}}$, Vania Vezzosi ${ }^{\mathrm{c}}$, \\ Virginia Valentini ${ }^{\text {b }}$, Simonetta Bianchi ${ }^{\text {, }}$, Laura Ottini ${ }^{\text {b, }}{ }^{\text {, Giovanna Masala }}{ }^{\text {a, }}$ \\ ${ }^{a}$ Cancer Risk Factors and Lifestyle Epidemiology Unit, Institute for cancer research, prevention and clinical network (ISPRO), Via Delle Oblate 4, 50141 \\ Florence, Italy \\ b Department of Molecular Medicine, Sapienza University of Rome, Viale Regina Elena N. 324, 00161 Rome, Italy \\ ${ }^{\mathrm{c}}$ Division of Pathological Anatomy, Department of Medical and Surgical Critical Care, University of Florence, Largo Brambilla, 3, 50134 Florence, Italy
}

\section{A R T I C L E I N F O}

\section{Article history:}

\section{Keywords:}

Breast cancer

Male

Cigarette smoking

FGFR2

Survival

Population-based study

\begin{abstract}
A B S T R A C T
Aim: Male breast cancer (MBC) is a rare disease and recommendations for its clinical management are often extrapolated from those for female breast cancer, even if breast cancer (BC) has different characteristics in the two sexes. The purpose of this study was to assess the influence of several individual characteristics including clinico-pathological, lifestyle and genetic factors on overall survival (OS) of a relatively large and well characterized population-based series of $166 \mathrm{MBCs}$ enrolled in Tuscany. Methods: We genotyped MBC cases at BRCA1/2 genes and at 9 candidate BC susceptibility SNPs. KaplanMeier method and multivariate Cox regression, adjusted for several individual characteristics were used. To reduce a possible selection bias related to the interval between diagnosis and enrolment of MBC cases into the study, we used the date of blood donation as the date of the start of observation for survival analysis.

Results: Only smoking habits had a significant effect on OS at 10 years (for current smokers, HR: 3.34; $95 \%$ CI 1.45-7.68; $\mathrm{p}=0.004$ ), while lymph node status fell short of reaching statistical significance (for pN positive, HR: $2.07 ; 95 \% \mathrm{CI} 0.93-4.55 ; \mathrm{p}=0.07)$. In the same multivariate analysis we found a significantly higher OS in cases with FGFR2 rs2981582 variant in the dominant transmission model (HR: 0.29 ; $95 \%$ CI: $0.13-0.62 ; \mathrm{p}=0.028)$. A sensitivity analysis with left truncation showed similar results. Conclusions: Our results may contribute to shed light on factors influencing MBC survival suggesting an important role for cigarette smoking and FGFR2 rs2981582 variant, and provide clues for better patient management.
\end{abstract}

() 2018 Elsevier Ltd. All rights reserved.

\section{Introduction}

Male breast cancer $(\mathrm{MBC})$ is a rare disease accounting for $<1 \%$ of all cancers in men [1]. Some studies suggest a worse outcome for

Abbreviations: MBC, Male breast cancer; BC, Breast cancer; FBC, Female breast cancer; SNP, Single-nucleotide polymorphism; GWAS, Genome-wide association studies; FH, Family history; OS, Overall survival; K-M, Kaplan-Meier method; HR, Hazard Ratio; CI, Confidence Interval; MI, Multiple imputation; MICE, Multivariate imputation by chained equations; FGFR2, Fibroblast growth factor receptor 2; PAH, Polycyclic aromatic hydrocarbons; DSBR, Double strand break repair.

* Corresponding author. Cancer Risk Factors and Lifestyle Epidemiology Unit, Institute for Cancer Research, Prevention and Clinical Network (ISPRO), Via delle Oblate 4, 50141 Florence, Italy.

E-mail address: d.palli@ispo.toscana.it (D. Palli).

1 Co-last authors.
MBC patients compared with female breast cancer (FBC) cases, largely due to delay in diagnosis and associated comorbidities for the advanced age of the patients [2]. Furthermore, depending on the paucity of data, recommendations for MBC are often extrapolated from those for FBC. Nevertheless, even if MBC and FBC share similarities in terms of genetic, environmental and lifestyle risk factors, BC is biologically different in the two genders [3,4]. Thus, there is the need to better understand this disease identifying male-specific factors influencing survival and providing the basis for a better patient management.

Most of the retrospective studies evaluating "traditional" clinico-pathological prognostic factors of MBCs show conflicting results [5-7]. Individual characteristics such as age and marital status have been detected as independent prognostic factors for MBC survival in some studies [8, 9]. Among lifestyle factors, the 
impact of tobacco smoking has not yet been fully elucidated. A recent study carried out on 1,573 MBC cases provided the first evidence that smokers at the time of diagnosis have a worse survival than never smokers, with a significant linear dose-response of smoking intensity [10]. In the effort to identify predictors of MBC survival, host genetic characteristics cannot be ignored. Results on prognostic significance of BRCA mutations are not consistent [1113] and in FBC, the relationship between susceptibility SNPs, identified in genome-wide association studies, and prognosis is not yet been established with some exceptions [14, 15].

To our best knowledge, no study on the association among SNPs and survival in MBC series has been performed. In a previous study, we tested nine susceptibility variants identifying common variants at ESR1 and TOX3 loci playing a role in MBC susceptibility [4]. Thus, we hypothesized that these SNPs might also be associated with MBC prognosis. The aim of this study was therefore to assess whether different individual characteristics, including selected genetic and lifestyle factors, affect survival in a well-characterized population-based series of $166 \mathrm{MBC}$ cases, enrolled in Tuscany (Central Italy).

\section{Material and methods}

\subsection{MBC patients recruitment}

In the present study, we expanded the original populationbased series of $108 \mathrm{MBC}$ cases previously described [16] enrolling 58 additional MBC cases, diagnosed in the period $1980-2015$, for a total of $166 \mathrm{MBC}$ residing in Tuscany.

The recruitment of the new cases was carried out according to the same protocol used for the previous MBC series. Overall, after exclusion of deceased and migrated patients, 63 additional unrelated MBC were traced and invited to participate into the study. Five cases refused to participate, mostly because of advanced age or severe illness, thus confirming our previous high response rate (92.1\%).

For each study participant we obtained: 1) a signed informed consent form; 2) detailed information on his personal and familial history of cancer at any sites validated by the local Cancer and Mortality Registries; 3 ) information on lifestyle habits, collected by standardized EPIC questionnaires [17]; 4) a detailed occupational history up to the date of MBC diagnosis; 5) a peripheral blood sample.

Clinico-pathological data were collected through several approaches, including retrieval of medical records and pathological reports. Some individual data were not available for all cases.

Procedures to maintain confidentiality for all information collected were developed and strictly applied. The study was approved by the Florence Ethical Committee (prot. 0001192/2006).

\subsection{DNA extraction, mutation analysis and genotyping}

For each study participant DNA was extracted from peripheral blood lymphocytes using QIAamp DNA Blood mini kit (Qiagen, Venlo, The Netherlands), following manufacturer instructions. DNA samples were quantified using NanoDrop 1000 (Thermo Fisher Scientific, Waltham, Massachusetts, USA).

The entire BRCA1 and BRCA2 coding sequences were analyzed by combining single strand conformational polymorphism (SSCP), protein truncation test (PTT), and Sanger sequencing as previously described [4]. All cases negative for BRCA1/2 mutations were recently retested using Next Generation Sequencing [18]. All BRCA1/2 variants classified as pathogenic mutations were confirmed by Sanger sequencing. MBC cases were also genotyped by allelic discrimination real-time PCR with TaqMan probes at nine selected susceptibility SNPs as previously described [4].

\subsection{Statistical analysis}

Study variables included interval between diagnosis and blood donation, breast and/or ovarian cancer family history (FH), personal history of other cancers, marital status, smoking habits, tumour characteristics, BRCA mutational status and genotype of nine selected susceptibility SNPs.

Descriptive statistics to evaluate patients' characteristics were used. One of the problems in MBC studies is represented by the rarity of the disease. In order to increase the number of cases for meaningful statistical analyses, it has been necessary to enrol patients diagnosed over a long period of time and in a larger geographical area. To reduce a possible selection bias related to the interval between diagnosis and enrolment of $\mathrm{MBC}$ cases into the study, we used the date of blood donation as the date of the start of observation for survival analysis. Survival time was calculated from this date to the date of death from any cause (overall survival, OS) or the last follow-up (May 2016) for alive patients. All current analyses are focused on 10-year survival: all subjects alive at 10 years were censored as those with a shorter follow-up (67 patients at the last date). For each variable, OS was estimated using the Kaplan-Meier method (K-M), and differences between groups of patients were assessed by the log-rank test. Univariate Cox regression was also used.

Furthermore, multivariate regression analysis was carried out to assess the effect of each SNP according to either recessive or dominant transmission model taking into account other individual characteristics. In the dominant transmission model, both the heterozygous variant and the rare homozygous variant were combined in a dummy variable. In the recessive transmission model, the rare homozygous genotype variant was defined in a dummy variable. Multivariate Cox regression models including one SNP at a time (in the recessive or dominant transmission model) and selected individual characteristics were fitted with age as the primary time variable.

We also performed a sensitivity analysis with survival time beginning at the time of the diagnosis, adjusting for left truncation (delayed entry of enrolled MBC cases) [19]. In our series, we defined the left truncation time as the time from diagnosis to enrolment.

Since our dataset contained missing values for a few variables, multiple imputation $[20,21]$ was used to analyze the whole dataset. As recommended by Rezvan et al. [22], we produced 100 imputed datasets. P-values were adjusted using the Benjamini-Hochberg procedure for multiple testing [23]. All calculations were made in R 3.3.3 for Windows [24].

\section{Results}

\subsection{Clinico-pathological and genetic characteristics}

A total of 166 men with BC diagnosed between 1980 and 2015 were included in our study. Mean age at diagnosis was 64.3 years (SD: 11.5; range 24-91 years). We enrolled the cases after a mean interval diagnosis-blood donation of 4.7 years (SD: 4.4 ; median 3.6), thus the mean age at blood donation was 69 years (SD: 11.2). The main characteristics of MBC cases are shown in Table 1. Notably, five patients (3.0\%) had been diagnosed with bilateral BC. All MBC cases were genotyped at BRCA genes and at nine susceptibility SNPs (Table 2).

\section{Survival analysis}

\subsection{Kaplan-Meier survival analysis and univariate Cox regression}

In the follow-up, we identified 23 deaths at 5 years, and 51 at 10 
Table 1

Distribution of patients and Kaplan-Meier survival estimates according to selected individual characteristics (166 MBC patients, Tuscany, Italy).

\begin{tabular}{|c|c|c|c|c|c|c|c|c|}
\hline & \multirow{2}{*}{$\frac{\mathrm{N} \text { at start }}{(\%)}$} & \multicolumn{3}{|l|}{5 years $^{\mathrm{a}}$} & \multicolumn{3}{|c|}{10 years $^{\mathrm{a}}$} & \multirow[t]{2}{*}{$p$-value* } \\
\hline & & Deaths & At risk & $\% O S$ & Deaths & At risk & $\% O S$ & \\
\hline \multicolumn{9}{|l|}{ Interval diagnosis-blood donation } \\
\hline$<$ median ( 3.6 years) & $83(50.0)$ & 11 & 61 & 85.2 & 21 & 24 & 67.5 & \\
\hline$\geq$ median & $83(50.0)$ & 12 & 51 & 83.0 & 30 & 26 & 50.1 & 0.100 \\
\hline \multicolumn{9}{|l|}{ BC/OC family history } \\
\hline Negative & $88(53.0)$ & 11 & 66 & 86.0 & 32 & 29 & 54.5 & \\
\hline Positive & $78(47.0)$ & 12 & 46 & 81.7 & 19 & 21 & 64.8 & 0.566 \\
\hline \multicolumn{9}{|l|}{ Personal history of other cancers } \\
\hline Negative & $138(83.1)$ & 18 & 96 & 85.2 & 40 & 43 & 61.1 & \\
\hline Positive & $28(16.9)$ & 5 & 17 & 77.5 & 11 & 7 & 42.6 & 0.132 \\
\hline \multicolumn{9}{|l|}{ Marital status } \\
\hline Single, widowed, separated or divorced & $130(7.8)$ & 2 & 11 & 83.3 & 4 & 6 & 64.8 & \\
\hline Married & $153(92.2)$ & 21 & 102 & 84.2 & 47 & 44 & 57.5 & 0.640 \\
\hline \multicolumn{9}{|l|}{ Smoker } \\
\hline Never/Former & $133(80.1)$ & 17 & 90 & 85.1 & 37 & 40 & 61.6 & \\
\hline Current & $33(19.9)$ & 6 & 23 & 79.7 & 14 & 10 & 47.6 & 0.274 \\
\hline \multicolumn{9}{|l|}{ Tumour behaviour ** } \\
\hline In situ & $17(10.5)$ & 0 & 14 & 100.0 & 1 & 6 & 88.9 & \\
\hline Invasive & $145(89.5)$ & 23 & 95 & 81.7 & 49 & 42 & 54.7 & 0.037 \\
\hline \multicolumn{9}{|l|}{ UICC Stage ** } \\
\hline $\mathrm{I}-\mathrm{II}$ & $121(85.8)$ & 15 & 86 & 85.9 & 35 & 37 & 61.5 & \\
\hline III-IV & $20(14.2)$ & 4 & 13 & 77.3 & 8 & 7 & 48.2 & 0.435 \\
\hline \multicolumn{9}{|l|}{ Histological type ${ }^{* *}$} \\
\hline Other & $16(10.0)$ & 1 & 13 & 92.9 & 2 & 7 & 84.4 & \\
\hline Ductal & $144(90.0)$ & 21 & 95 & 83.0 & 46 & 42 & 56.1 & 0.094 \\
\hline \multicolumn{9}{|l|}{ Tumour grading $* *$} \\
\hline I - II & $100(71.4)$ & 10 & 72 & 88.7 & 29 & 33 & 60.2 & \\
\hline III & $40(28.6)$ & 8 & 27 & 77.2 & 14 & 11 & 54.0 & 0.374 \\
\hline \multicolumn{9}{|l|}{$\mathbf{p N}^{* *}$} \\
\hline Negative & $78(62.9)$ & 10 & 52 & 84.8 & 15 & 28 & 73.6 & \\
\hline Positive & $46(37.1)$ & 9 & 29 & 78.0 & 20 & 8 & 41.9 & 0.006 \\
\hline \multicolumn{9}{|l|}{$\mathbf{E R}^{* *}$} \\
\hline Negative & $140(9.6)$ & 4 & 12 & 73.3 & 8 & 8 & 46.7 & \\
\hline Positive & $132(90.4)$ & 13 & 90 & 88.1 & 32 & 39 & 64.0 & 0.039 \\
\hline \multicolumn{9}{|l|}{$\mathbf{P R}^{* *}$} \\
\hline Negative & $23(15.9)$ & 1 & 20 & 95.5 & 8 & 10 & 56.3 & \\
\hline Positive & $122(84.1)$ & 16 & 82 & 84.6 & 32 & 37 & 64.0 & 0.864 \\
\hline \multicolumn{9}{|l|}{ HER2 ${ }^{* *}$} \\
\hline Negative & $103(81.7)$ & 11 & 76 & 87.9 & 30 & 37 & 61.5 & \\
\hline Positive & $23(18.3)$ & 4 & 16 & 80.1 & 7 & 9 & 63.1 & 0.831 \\
\hline \multicolumn{9}{|l|}{ Biological type ${ }^{* *}$} \\
\hline Luminal A & $93(70.4)$ & 10 & 66 & 87.4 & 25 & 31 & 62.4 & \\
\hline Luminal B & $20(22.0)$ & 3 & 14 & 82.2 & 5 & 8 & 68.3 & 0.830 \\
\hline HER2 & $30(2.3)$ & 1 & 3 & 66.7 & 2 & 2 & 33.3 & 0.143 \\
\hline $\mathrm{TN}$ & $70(5.3)$ & 0 & 1 & 66.7 & 2 & 5 & 66.7 & 0.780 \\
\hline All patients & 166 & 23 & 112 & 84.0 & 51 & 49 & 58.2 & \\
\hline
\end{tabular}

${ }^{*} p$-value from the log-rank test assessed at 10 years after enrolment.

**some data are missing.

a after enrolment into the cohort (date of blood donation).

years after blood donation. Tables 1 and 2 show the K-M survival analysis according to selected characteristics: the 5-year OS was $84 \%$, while 10 -year OS was $58.2 \%$. Survival curves with significant log-rank tests are shown in Figure 1. Results from univariate Cox regression models for ER and BRCA2 mutation status were consistent with K-M survival analysis $(\mathrm{p}=0.019$ and $\mathrm{p}=0.050$, respectively). The risk of death related to $\mathrm{pN}$ status resulted of borderline statistical significance $(\mathrm{p}=0.073)$. Among lifestyle factors, current smokers showed a significant increased risk of death $(\mathrm{p}=0.007)$ (data not shown).

\subsection{Multivariate Cox regression}

In multivariate analyses we fitted several regression models, each one including one SNP at a time (in the recessive or dominant transmission model) adjusted for selected individual characteristics and with age as the primary time variable. Only the regression including fibroblast growth factor receptor 2 (FGFR2) rs2981582 variant in the dominant transmission model showed a significant decreased risk of death at 10 years after enrolment (HR: $0.29 ; 95 \%$ CI: 0.13-0.62; $\mathrm{p}=0.028$ ) (Table 3).

Among lifestyle factors, only smoking habits had a significant effect on OS, with current smokers showing an increased risk of death (HR: 3.34; 95\% CI 1.45-7.68; $\mathrm{p}=0.004$ ). Difference in OS due to lymph node status resulted only of borderline statistical significance (HR: 2.07; 95\% CI 0.93-4.55; $\mathrm{p}=0.071$ ).

The sensitivity analysis with left truncation showed similar results. We found at 10 years after diagnosis a significantly increased risk of death for current smokers (HR: 3.82; 95\% CI 1.09-13.41; $\mathrm{p}=0.037)$ and a significantly decreased risk of death for FGFR2 rs2981582 variant in the dominant transmission model (HR: 0.32; 95\% CI: $0.12-0.87 ; \mathrm{p}=0.026$ ). After multiple comparison adjustment the latter effect of FGFR2 rs2981582 variant did not reach the level of statistical significance (data not shown).

\section{Discussion}

In this population-based series of $166 \mathrm{MBC}$ enrolled in Tuscany 
Table 2

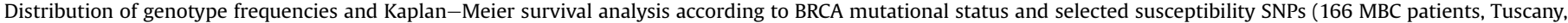
Italy).

\begin{tabular}{|c|c|c|c|c|c|c|c|c|}
\hline & \multirow{2}{*}{$\frac{\mathrm{N} \text { at start }}{(\%)}$} & \multicolumn{3}{|l|}{ 5-years ${ }^{\mathrm{a}}$} & \multicolumn{3}{|c|}{10 years $^{\mathrm{a}}$} & \multirow[t]{2}{*}{$p$-value } \\
\hline & & Deaths & At risk & $\% \mathrm{OS}$ & Deaths & At risk & $\% \mathrm{OS}$ & \\
\hline \multicolumn{9}{|l|}{ BRCA status } \\
\hline Wild type & $144(86.8)$ & 19 & 99 & 84.8 & 43 & 45 & 60.0 & \\
\hline BRCA1 mutated & $40(2.4)$ & 0 & 4 & 100.0 & 0 & 3 & 100.0 & 0.212 \\
\hline BRCA2 mutated & $18(10.8)$ & 4 & 10 & 72.4 & 8 & 3 & 29.0 & 0.036 \\
\hline \multicolumn{9}{|c|}{ CASP8 rs 1045485} \\
\hline GG & $118(71.1)$ & 19 & 80 & 81.8 & 38 & 38 & 58.3 & \\
\hline GC & $44(26.5)$ & 3 & 30 & 91.6 & 12 & 12 & 56.8 & 0.746 \\
\hline $\mathrm{CC}$ & $40(2.4)$ & 1 & 3 & 66.7 & 1 & 1 & 66.7 & 0.962 \\
\hline \multicolumn{9}{|l|}{ 19p13 rs2363956 } \\
\hline GG & $42(25.3)$ & 8 & 26 & 78.3 & 15 & 9 & 51.6 & \\
\hline GT & $83(50.0)$ & 12 & 55 & 83.5 & 26 & 31 & 59.0 & 0.875 \\
\hline $\mathrm{TT}$ & $41(24.7)$ & 3 & 31 & 91.4 & 10 & 12 & 62.9 & 0.365 \\
\hline \multicolumn{9}{|l|}{ 2q35 rs13387042 } \\
\hline GG & $37(22.3)$ & 5 & 26 & 84.7 & 8 & 13 & 73.0 & \\
\hline GA & $79(47.6)$ & 8 & 56 & 88.2 & 23 & 25 & 59.6 & 0.480 \\
\hline AA & $50(30.1)$ & 10 & 31 & 77.1 & 20 & 13 & 46.0 & 0.073 \\
\hline \multicolumn{9}{|l|}{ 5p12 rs10941679 } \\
\hline $\mathrm{AA}$ & $93(56.0)$ & 14 & 64 & 83.2 & 30 & 28 & 57.0 & \\
\hline AG & $62(37.4)$ & 7 & 43 & 86.2 & 19 & 20 & 57.2 & 0.815 \\
\hline GG & $110(6.6)$ & 2 & 7 & 76.2 & 2 & 4 & 76.2 & 0.594 \\
\hline \multicolumn{9}{|l|}{ ESR1 rs2046210 } \\
\hline $\mathrm{CC}$ & $51(30.7)$ & 5 & 37 & 88.4 & 16 & 15 & 55.1 & \\
\hline $\mathrm{CT}$ & $82(49.4)$ & 11 & 53 & 84.3 & 24 & 25 & 58.9 & 0.836 \\
\hline TT & $33(19.9)$ & 7 & 23 & 77.3 & 11 & 11 & 62.1 & 0.768 \\
\hline \multicolumn{9}{|l|}{ FGFR2 rs2981582 } \\
\hline GG & $38(22.9)$ & 9 & 22 & 73.3 & 14 & 7 & 44.1 & \\
\hline GA & $82(49.4)$ & 11 & 52 & 83.8 & 26 & 24 & 55.9 & 0.668 \\
\hline $\mathrm{AA}$ & $46(27.7)$ & 3 & 38 & 92.8 & 11 & 20 & 70.5 & 0.076 \\
\hline \multicolumn{9}{|l|}{ LSP1 rs3817198 } \\
\hline TT & $74(44.6)$ & 9 & 53 & 86.3 & 22 & 24 & 61.5 & \\
\hline TC & $70(42.2)$ & 11 & 43 & 81.4 & 22 & 19 & 54.0 & 0.466 \\
\hline $\mathrm{CC}$ & $22(13.2)$ & 3 & 16 & 85.0 & 7 & 9 & 60.0 & 0.861 \\
\hline \multicolumn{9}{|c|}{ MAР3K1 rs889312 } \\
\hline $\mathrm{AA}$ & $77(46.4)$ & 9 & 54 & 86.6 & 25 & 23 & 54.9 & \\
\hline AC & $73(44.0)$ & 12 & 49 & 81.6 & 23 & 23 & 59.1 & 0.824 \\
\hline $\mathrm{CC}$ & $160(9.6)$ & 2 & 10 & 81.8 & 3 & 6 & 72.7 & 0.499 \\
\hline \multicolumn{9}{|l|}{ TOX3 rs3803662 } \\
\hline $\mathrm{CC}$ & $55(33.1)$ & 8 & 35 & 83.2 & 15 & 17 & 63.2 & \\
\hline $\mathrm{CT}$ & $82(49.4)$ & 11 & 56 & 84.4 & 26 & 25 & 57.1 & 0.743 \\
\hline TT & $29(17.5)$ & 4 & 21 & 84.9 & 10 & 10 & 53.6 & 0.911 \\
\hline All patients & 166 & 23 & 112 & 84.0 & 51 & 49 & 58.2 & \\
\hline
\end{tabular}

${ }^{*} p$-value from the log-rank test assessed at 10 years after enrolment.

a after enrolment into the cohort (date of blood donation).

(Italy), we found that cigarette smoking and the variant allele of rs2981582 in the FGFR2 gene significantly affect OS.

Due to low incidence and limited research, little is known about the factors affecting MBC survival, and to our best knowledge this is the first population-based study addressing the subject.

Taking into account "traditional" clinico-pathological variables, our multivariate survival analysis suggests, in line with other studies [25], the importance of lymph node involvement in MBC prognosis although it doesn't reach statistical significance.

With regard to epidemiological variables, we found a worse prognosis in current smokers compared to never/former smokers. The relationship between smoking habits and survival in BC has been extensively studied in females, mainly in Western countries, with conflicting results. Some studies showed that current and former smokers were at higher risk of all-cause death after BC diagnosis, whereas others failed to report this association [26,27]. Moreover, it has been shown that smokers tend to have more comorbidities and more advanced disease than non-smokers, even after adjustment for clinical characteristics [28]. The results of the only study performed recently on 1,573 MBC cases showed a significant inverse association of survival with smoking intensity, also reported in $\mathrm{FBC}$, and suggested that smoking might have more influence on MBC than on FBC survival and that the effect of smoking on survival could be affected by race, pointing to different genetic and molecular pathways [10].

Notably, evidence provided by several studies indicates a relationship between occupational and environmental exposures and $\mathrm{MBC}$ risk. Interestingly, in a previous study, we reported a modifying effect on $\mathrm{MBC}$ risk due to occupational exposure to polycyclic aromatic hydrocarbons (PAH), in subjects carrying BRCA2 germline mutations [29].

Here, our results confirm that cigarette smoke, a mixture of chemical compounds including $\mathrm{PAH}$ and other carcinogenic substances, might affect survival in MBC. This effect could be explained by the genetic context of $\mathrm{MBC}$, partly consisting of defective highand low-penetrance predisposition genes involved in DNA damage response. In addition, the relationship between smoking and MBC survival might be due to the negative effect of long-term smoking on the immune system and to the estrogenic effect of some compounds present in tobacco smoke that could be more relevant in men, without reproductive and hormonal factors, than in women, in whom anti-estrogenic effect of smoking has long been known [30,31].

Some studies aimed to identify genetic markers associated with 

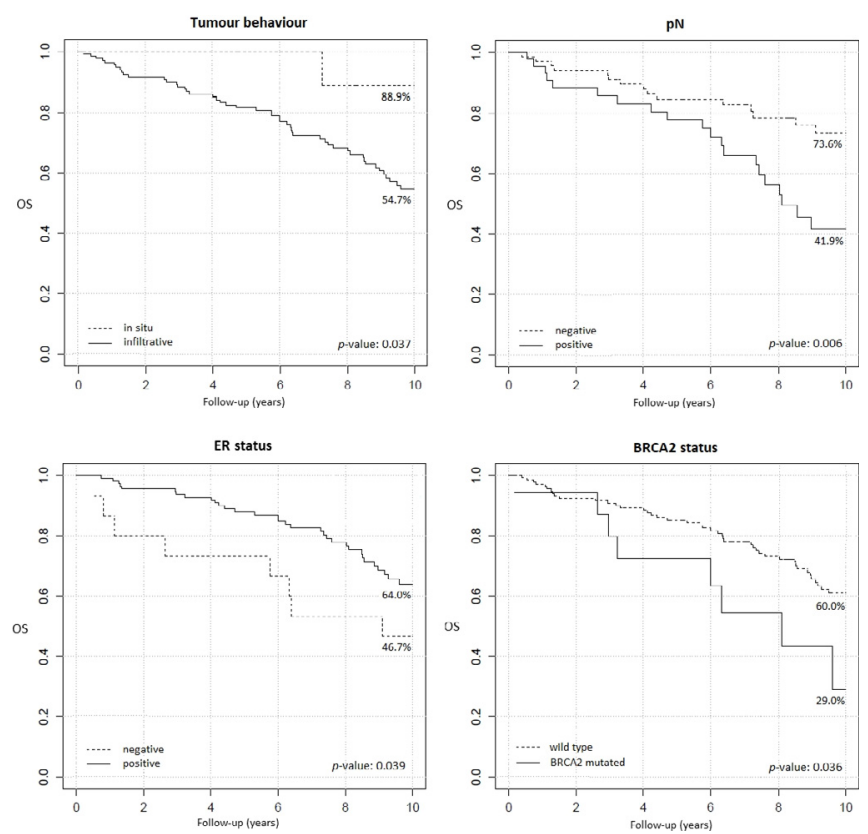

Figure 1. Kaplan-Meier survival curves with significant log-rank test for selected variables in a series of $166 \mathrm{MBC}$ patients enrolled in Tuscany (Italy).

\section{Table 3}

Estimates of the risk of death at 10 years based on a multivariate Cox proportional regression including all the listed variables and the FGFR2 rs2981582 variant in the dominant transmission model (166 MBC patients, Tuscany, Italy). Multiple imputation via chained equations (100 imputed datasets) was used.

\begin{tabular}{|c|c|c|c|}
\hline & $\mathrm{HR}^{\mathrm{a}}$ & $95 \% \mathrm{CI}$ & $p$-value \\
\hline \multicolumn{4}{|l|}{ Interval diagnosis-blooda donation } \\
\hline$<$ median ( 3.6 years) & 1.00 & & \\
\hline$\geq$ median & 1.46 & $0.73-2.91$ & 0.280 \\
\hline \multicolumn{4}{|l|}{ Smoker } \\
\hline Never/Former & 1.00 & & \\
\hline Current & 3.34 & $1.45-7.68$ & 0.004 \\
\hline \multicolumn{4}{|l|}{ Tumour behaviour } \\
\hline In situ & 1.00 & & \\
\hline Invasive & 2.77 & $0.35-21.59$ & 0.331 \\
\hline \multicolumn{4}{|l|}{ Histological type } \\
\hline Other & 1.00 & & \\
\hline Ductal & 2.00 & $0.43-9.20$ & 0.375 \\
\hline \multicolumn{4}{|l|}{ Tumour grading } \\
\hline $\mathrm{I}-\mathrm{II}$ & 1.00 & & \\
\hline III & 0.79 & $0.35-1.78$ & 0.572 \\
\hline \multicolumn{4}{|l|}{ pN } \\
\hline Negative & 1.00 & & \\
\hline Positive & 2.07 & $0.93-4.55$ & 0.071 \\
\hline \multicolumn{4}{|l|}{ ER } \\
\hline Negative & 1.00 & & \\
\hline Positive & 0.45 & $0.17-1.18$ & 0.106 \\
\hline \multicolumn{4}{|l|}{ PR } \\
\hline Negative & 1.00 & & \\
\hline Positive & 1.24 & $0.48-3.20$ & 0.658 \\
\hline \multicolumn{4}{|l|}{ HER2 } \\
\hline Negative & 1.00 & & \\
\hline Positive & 1.44 & $0.53-3.92$ & 0.478 \\
\hline \multicolumn{4}{|l|}{ BRCA status } \\
\hline Wild type & 1.00 & & \\
\hline BRCA1 mutation & $<0.01$ & - & 0.997 \\
\hline BRCA2 mutation & 1.73 & $0.66-4.53$ & 0.264 \\
\hline \multicolumn{4}{|l|}{ FGFR2 rs2981582 (dominant model) } \\
\hline Wild type & 1.00 & & \\
\hline Heterozygous/homozygous variant & 0.29 & $0.13-0.62$ & 0.028* \\
\hline
\end{tabular}

FBC specific survival [14,15, 32-35], but to our best knowledge, no study on the association among SNPs and survival in MBC series has been performed.

In the frame of a large Italian multicenter study, we showed that common low penetrance BC susceptibility alleles modulate MBC risk $[4,36]$. Thus, in addition to epidemiological variables, we explored the possible role of such variants in MBC prognosis. In this study, a higher rate of survival was observed in patients carrying the variant allele of rs2981582 in FGFR2 gene. The protein encoded by this gene is a member of the fibroblast growth factor receptor family and is a receptor tyrosine kinase involved in cell proliferation, differentiation, migration, apoptosis and double strand break repair (DSBR) [37,38]. FGFR2 was one of the first genes identified to be associated with the susceptibility to BC in GWAS. Interestingly, in intron 2 of the gene, up to eight variants have been identified, including rs2981582, that are located in a linkage disequilibrium block and are more likely to predispose patients to ER + low grade BC $[37,39]$.

In the clinical field, high expression levels of cytoplasmic and nuclear FGFR2 were associated with lower OS, but in patients who received chemotherapy, high expression of FGFR2 was associated with better prognosis $[37,40]$. Probably, high expression of FGFR2 reduces DSBR activity, which may increase sensitivity to chemotherapeutic agents causing DSB formation such as doxorubicin and etoposide [38].

To our best knowledge, the role of FGFR2 variants in MBC prognosis have not been investigated so far. In a study performed on FBC Tunisian cases, a higher OS rate was observed in patients carrying the FGFR2 rs1219648 variant allele, reported to be in high linkage disequilibrium $\left(\mathrm{r}^{2}=1\right)$ with FGFR2 rs2981582 in HapMap database [41].

It is interesting to note that, in male patients with primary prostate cancer, both previously cited FGFR2 SNPs were associated with more favourable OS [42]. These results are consistent with our findings and support the hypothesis that rs2981582 SNP might play a role in MBC survival.

The mechanism underlying the effect of rs2981582 SNP is still unknown. The FGFR2 rs2981582 variant not only affects FGFR2 mRNA level by altering the binding of transcription regulators, but is also involved in the increase of FGFR2 signalling activity [43] that could affect downstream FGFR2 targets creating conditions for a better survival.

In our study, no role for BRCA mutations emerged in multivariate analyses, although univariate analyses showed a detrimental effect of BRCA2 mutations in modulating OS. The latter was is in line with our observation that BRCA2 MBC may be more aggressive, being of higher stage and histologic grade [44]. Overall, however, these genes, involved in FBC and MBC susceptibility, do not appear to play a central role in MBC survival.

In order to characterize our series from a genetic point of view, we collected a blood sample for each participant, so we recruited a population-based series of MBC patients still alive at the date of contact, that is a group of survivors. This represents a limitation in survival analysis, and to reduce a possible selection bias due to the loss of early deaths, we considered the blood donation as the start of observation. However, we also performed a sensitivity analysis with the date of diagnosis as the start of observation adjusted for delayed entry or left truncation (time from diagnosis to enrolment), and we obtained similar results in terms of death risks associated to selected individual parameters. Because of the different time scales, the number of events was lower in the 10 year-period after diagnosis considered in this sensitivity analysis and the levels of statistical significance differed.

Another limitation of our study is that the smoking status was assessed at diagnosis so it cannot be excluded that some patients quit smoking after diagnosis. 
However, the strength of our study is to have a homogeneous and well characterized population-based series of MBC cases with detailed information about clinico-pathological, genetic and lifestyle-related variables.

In conclusion, our study allowed us to explore the factors influencing $\mathrm{MBC}$ survival, suggesting an important role for smoking history and FGFR2 rs2981582 variant. Nevertheless, our findings should be regarded with caution and their clinical implications are at present uncertain. On one hand, having identified smoking as an unfavourable but potentially modifiable prognostic factor, may be of importance to public health because suggests the possibility to activate tertiary prevention protocols for promoting smoking cessation in MBC cases. On the other hand, having identified FGFR2 rs2981582 variant as favourable prognostic factor supports the hypothesis that survival in MBC may be influenced by a distinct set of germline variants among those influencing susceptibility.

These results provide interesting clues for further research aimed at elucidating the possible role of lyfestyle and genetic factors on MBC survival. Large-scale multicenter studies are warranted to verify the importance of these factors in this understudied disease.

\section{Funding}

This work was supported by the ITT (Istituto Toscano Tumori) grant [2010] to D.P. and by Associazione Italiana per la Ricerca sul Cancro [AIRC IG 16933] to L.O.

\section{Conflicts of interest}

The authors declare that they have no conflict of interest.

\section{Ethical approval}

The study has been approved by the Florence Ethical Committee (prot. 0001192/2006) and has been performed in accordance with the ethical standards as laid down in the 1964 Helsinki declaration and its later amendments or comparable ethical standards.

\section{Informed consent}

Informed consent was obtained from all individual participants included in the study.

\section{Acknowledgments}

We thank all the patients participating in the study and their general practioners for collaboration. In addition we thank Dr.s Mauro Biancalani, Carmelo Urso, Augusto Giannini and Paola Apicella (Pathology Departments, Central Tuscany USL); Dr.s Andrea Cavazzana, Claudio Sabò and Laura Pfanner (Pathology Departments, North-Western Tuscany USL); Dr.s Francesco Mirri, Calogera La Magra, Tiziana Megha and Michela Stumpo (Pathology Departments, South-Eastern Tuscany USL) for their help with histologic confirmation.

The study was carried out in the frame of the ongoing High-Risk Cancer Family Project.

\section{References}

[1] Ly D, Forman D, Ferlay J, Brinton LA, Cook MB. An international comparison of male and female breast cancer incidence rates. Int J Cancer 2013;132(8): $1918-26$.

[2] Abreu MH, Afonso N, Abreu PH, Menezes F, Lopes P, Henrique R, et al. Male breast cancer: Looking for better prognostic subgroups. Breast 2016;26: $18-24$.
[3] Fentiman IS. Male breast cancer is not congruent with the female disease. Crit Rev Oncol Hematol 2016;101:119-24.

[4] Ottini L, Silvestri V, Saieva C, Rizzolo P, Zanna I, Falchetti M, et al. Association of low-penetrance alleles with male breast cancer risk and clinicopathological characteristics: results from a multicenter study in Italy. Breast Cancer Res Treat 2013;138:861-8.

[5] Soliman AA, Denewer AT, El-Sadda W, Abdel-Aty AH, Refky B A retrospective analysis of survival and prognostic factors of male breast cancer from a single center. BMC Cancer 2014;14:227.

[6] Vermeulen MA, Slaets L, Cardoso F, Giordano SH, Tryfonidis K, van Diest PJ, et al. Pathological characterisation of male breast cancer: results of the EORTC 10085/TBCRC/BIG/NABCG international male breast cancer program. Eur J Canc 2017;82:219-27.

[7] Cardoso F, Bartlett JMS, Slaets L, van Deurzen CHM, van Leeuwen-Stok E Porter P, et al. Characterization of male breast cancer: results of the EORTC 10085/TBCRC/BIG/NABCG international male breast cancer program. Ann Oncol 2018;29:405-17.

[8] Adekolujo OS, Tadisina S, Koduru U, Gernand J, Smith SJ, Kakarala RR. Impact of marital status on tumor stage at diagnosis and on survival in male breas cancer. Am J Mens Health 2016;11(4):1190-9.

[9] Leone JP, Leone J, Zwenger AO, Iturbe J, Leone BA, Vallejo CT. Locoregiona treatment and overall survival of men with T1a,b,cNOMO breast cancer: a population-based study. Eur J Cancer 2017;71:7-14.

[10] Padron-Monedero A, Koru-Sengul T, Tannenbaum SL, Miao F, Hansra D, Lee DJ, et al. Smoking and survival in male breast cancer patients. Breast Cancer Res Treat 2015;153:679-87.

[11] Zhong Q, Peng HL, Zhao X. Zhang L, Hwang WT. Effects of BRCA1- and BRCA2-related mutations on ovarian and breast cancer survival: a meta-analysis. Clin Cancer Res 2015;21(1):211-20.

[12] Cortesi L, Masini C, Cirilli C, Medici V, Marchi I, Cavazzini G, et al. Favourable ten-year overall survival in a Caucasian population with high probability of hereditary breast cancer. BMC Cancer 2010;10:90.

[13] Gargiulo P, Pensabene M, Milano M, Arpino G, Giuliano M, Forestieri V, et al. Long-term survival and BRCA status in male breast cancer: a retrospective single-center analysis. BMC Cancer 2016;16:375.

[14] Fasching PA, Pharoah PD, Cox A, Nevanlinna H, Bojesen SE, Karn T, et al. The role of genetic breast cancer susceptibility variants as prognostic factors. Hum Mol Genet 2012;21(17):3926-39.

[15] Barrdahl M, Canzian F, Lindström S, Shui I, Black A, Hoover RN, et al. Association of breast cancer risk loci with breast cancer survival. Int J Cancer 2015:137(12):2837-45.

[16] Ottini L, Rizzolo P, Zanna I, Falchetti M, Masala G, Ceccarelli C, et al. BRCA1/ BRCA2 mutation status and clinical-pathologic features of 108 male breast cancer cases from Tuscany: a population-based study in central Italy. Breast Cancer Res Treat 2009;116:577-86.

[17] Palli D, Berrino F, Vineis P, Tumino R, Panico S, Masala G, et al. EPIC-Italy. A molecular epidemiology project on diet and cancer: the EPIC-Italy prospective study. Design and baseline characteristics of participants. Tumori 2003;89:86-93.

[18] Rizzolo P, Silvestri V, Ottini L. Retesting BRCA1/BRCA2 mutation negative male breast cancer patients using next generation sequencing technologies. Breast Cancer Res Treat 2017:162(1):199-200.

[19] Cain KC, Harlow SD, Little RJ, Nan B, Yoseph M, Taffe JR, et al. Bias due to left truncation and left censoring in longitudinal studies of developmental and disease process. Am J Epidem 2011;173:1078-84.

[20] Rubin DB. Multiple imputation for nonresponse in surveys. New York: John Wiley \& Sons; 1987.

[21] Schafer JL. Multiple imputation: a primer. Stat Methods Med Res 1999;8(1): $3-15$.

[22] Rezvan PH, Lee KJ, Simpson JA. The rise of multiple imputation: a review of the reporting and implementation of the method in medical research. BMC Med Res Methodol 2015;15:30.

[23] Benjamini Y, Hochberg Y. Controlling the false discovery rate: a practical and powerful approach to multiple testing. J royal stat soc series B,. Stat Methodol 1995;57(1):289-300.

[24] Core Team R. R: a language and environment for statistical computing. Vienna, Austria: R Foundation for Statistical Computing; 2017. http://www. $\mathrm{R}$-project.org/.

[25] Soliman AA, Denewer AT, El-Sadda W, Abdel-Aty AH, Refky B. A retrospective analysis of survival and prognostic factors of male breast cancer from a single center. BMC Cancer 2014;14:227.

[26] Warren GW, Kasza KA, Reid ME, Cummings KM, Marshall JR. Smoking at diagnosis and survival in cancer patients. Int J Cancer 2013;132:401-10.

[27] Pierce JP, Patterson RE, Senger CM, Flatt SW, Caan BJ, Natarajan L, et al. Lifetime cigarette smoking and breast cancer prognosis in the after Breast Cancer Pooling Project. J Natl Cancer Inst 2014;106:359.

[28] Padron-Monedero A, Tannenbaum SL, Koru-Sengul T, Miao F, Hansra D, Lee DJ, et al. Smoking and survival in female breast cancer patients. Breast Cancer Res Treat 2015;150(2):395-403.

[29] Palli D, Masala G, Mariani-Costantini R, Zanna I, Saieva C, Sera F, et al. A geneenvironment interaction between occupation and BRCA1/BRCA2 mutations in male breast cancer. Eur J Cancer 2004;40(16):2474-9.

[30] Meek MD, Finch GL. Diluted mainstream cigarette smoke condensates activate estrogen receptor and aryl hydrocarbon receptor-mediated gene transcription. Environ Res 1999;80:9-17. 
[31] Cramer DW, Finn OJ. Epidemiologic perspective on immune-surveillance in cancer. Curr Opin Immunol 2011;23:265-71.

[32] Azzato EM, Tyrer J, Fasching PA, Beckmann MW, Ekici AB, SchulzWendtland R, et al. Association between a germline OCA2 polymorphism at chromosome 15q13.1 and estrogen receptor-negative breast cancer survival. J Natl Cancer Inst 2010;102(9):650-62.

[33] Guo Q, Schmidt MK, Kraft P, Canisius S, Chen C, Khan S, et al. Identification of novel genetic markers of breast cancer survival. J Natl Cancer Inst 2015; 107(5).

[34] Pirie A, Guo Q, Kraft P, Canisius S, Eccles DM, Rahman N, et al. Common germline polymorphisms associated with breast cancer-specific survival. Breast Cancer Res 2015;17:58.

[35] Fagerholm R, Khan S, Schmidt MK, Garcia-Closas M, Heikkila P, Saarela J, et al. TP53-based interaction analysis identifies cis-eQTL variants for TP53BP2 FBXO28, and FAM53A that associate with survival and treatment outcome in breast cancer. Oncotarget 2017;8(11):18381-98.

[36] Silvestri V, Rizzolo P, Scarnò M, Chillemi G, Navazio AS, Valentini V, et al. Novel and known genetic variants for male breast cancer risk at 8q24.21 9p21.3, 11q13.3 and 14q24.1: results from a multicenter study in Italy. Eur ] Cancer 2015;51(16):2289-95.

[37] Cui F, Wu D, Wang W, He X, Wang M. Variants of FGFR2 and their associations with breast cancer risk: a HUGE systematic review and meta-analysis. Breast Cancer Res Treat 2016;155(2):313-35.

[38] Huang YL, Chou WC, Hsiung CN, Hu LY, Chu HW, Shen CY. FGFR2 regulates Mre11 expression and double-strand break repair via the
MEK-ERK-POU1F1 pathway in breast tumorigenesis. Hum Mol Genet 2015:24(12):3506-17.

[39] Broeks A, Schmidt MK, Sherman ME, Couch FJ, Hopper JL, Dite GS, et al. Low penetrance breast cancer susceptibility loci are associated with specific breast tumor subtypes: findings from the Breast Cancer Association Consortium. Hum Mol Genet 2011;20(16):3289-303.

[40] Sun S, Jiang Y, Zhang G, Song H, Zhang X, Zhang Y, et al. Increased expression of fibroblastic growth factor receptor 2 is correlated with poor prognosis in patients with breast cancer. J Surg Oncol 2012;105(8):773-9.

[41] Shan J, Mahfoudh W, Dsouza SP, Hassen E, Bouaouina N, Abdelhak S, et al Genome-Wide Association Studies (GWAS) breast cancer susceptibility loci in Arabs: susceptibility and prognostic implications in Tunisians. Breast Cancer Res Treat 2012;135(3):715-24.

[42] Miles FL, Rao JY, Eckhert C, Chang SC, Pantuck A, Zhang ZF. Associations of immunity-related single nucleotide polymorphisms with overall survival among prostate cancer patients. Int J Clin Exp Med 2015;8(7):11470-6.

[43] Huijts PE, van Dongen M, De Goeij MC, Van Moolenbroek AJ, Blanken F, Vreeswijk MP, et al. Allele-specific regulation of FGFR2 expression is cell type-dependent and may increase breast cancer risk through a paracrine stimulus involving FGF10. Breast Cancer Res 2011;13(4):R72.

[44] Silvestri V, Barrowdale D, Mulligan AM, Neuhausen SL, Fox S, Karlan BY, et al., : Male breast cancer in BRCA1 and BRCA2 mutation carriers: pathology data from the Consortium of Investigators of Modifiers of BRCA1/2. Breast Cancer Res 2016:18(1):15. 